\title{
Application of Tin(II) Chloride Catalyst for High FFA Jatropha Oil Esterification in Continuous Reactive Distillation Column
}

\author{
Ratna Dewi Kusumaningtyas ${ }^{*}$, Imam Novrizal Aji ${ }^{1}$, H. Hadiyanto², Arief Budiman ${ }^{3}$ \\ ${ }^{1}$ Chemical Engineering Department, Faculty of Engineering, Semarang State University, Kampus \\ Unnes Sekaran, Semarang 50229, Indonesia \\ ${ }^{2}$ Chemical Engineering Department, Faculty of Engineering, Diponegoro University, Jl. Prof. H. \\ Soedarto, SH, Tembalang, Semarang 50275, Indonesia \\ ${ }^{3}$ Chemical Engineering Department, Faculty of Engineering, Gadjah Mada University, Jl Grafika 2 \\ Yogyakarta 55281, Indonesia
}

Received: 10 ${ }^{\text {th }}$ November 2015; Revised: $4^{\text {th }}$ February 2016; Accepted: $4^{\text {th }}$ February 2016

\begin{abstract}
The application of heterogeneous solid acid catalysts in biodiesel production has become popular and gained significant attention over the last few years. It is since these types of catalysts hold the benefits in terms of easy separation from the product, reusability of the catalyst, high selectivity of the reaction. They are also considered sustainable and powerful particularly in organic synthesis. This work studied the use of tin(II) chloride as solid Lewis acid catalyst to promote the esterification reaction of high Free Fatty Acid (FFA) jatropha oil in continuous reactive distillation column. To obtain the optimum condition, the influences of reaction time, molar ratio of the reactant, and catalyst were investigated. It was revealed that the optimum condition was achieved at the molar ratio of methanol to FFA at 1:60, catalyst concentration of $5 \%$, and reaction temperature of $60^{\circ} \mathrm{C}$ with the reaction conversion of $90 \%$. This result was significantly superior to the identical reaction performed using batch reactor. The esterification of high FFA jatropha oil using reactive distillation in the presence of tin(II) chloride provided higher conversion than that of Amberlyst- 15 heterogeneous catalyst and was comparable to that of homogenous sulfuric acid catalyst, which showed 30 and $94.71 \%$ conversion, respectively. The esterification reaction of high FFA jatropha oil was subsequently followed by transesterification reaction for the completion of the biodiesel production. Transesterification was carried out at $60{ }^{\circ} \mathrm{C}$, molar ratio of methanol to oil of $1: 6, \mathrm{NaOH}$ catalyst of $1 \%$, and reaction time of one hour. The jatropha biodiesel product resulted from this two steps process could satisfy the ASTM and Indonesian biodiesel standard in terms of ester content (97.79 \%), density, and viscosity. Copyright (C) 2016 BCREC GROUP. All rights reserved
\end{abstract}

Keywords: Tin(II) Chloride; esterification; jatropha oil; biodiesel; reactive distillation

How to Cite: Kusumaningtyas, R.D., Aji, I.N., Hadiyanto, H., Budiman, A. (2016). Application of Tin(II) Chloride Catalyst for High FFA Jatropha Oil Esterification in Continuous Reactive Distillation Column. Bulletin of Chemical Reaction Engineering \& Catalysis, 11 (1): 66-74.

(doi:10.9767/bcrec.11.1.417.66-74)

Permalink/DOI: http://dx.doi.org/10.9767/bcrec.11.1.417.66-74

* Corresponding Author.

E-mail: ratnadewi.kusumaningtyas@mail.unnes.ac.id

(R.D. Kusumaningtyas) 


\section{Introduction}

Biodiesel is among the prospective substitute of fossil fuel since it holds great environmental benefits, high cetane number, and high energy content [1]. It is also readily used in diesel fuel. Biodiesel can be synthesized from various vegetable oil feed-stocks. However, today's regulation stipulates that the feedstock for the energy production purpose should be non-edible raw material to avoid a competition with the food production [2]. In the case of biodiesel production system, non-edible vegetable oils or animal fats feedstock are priceless, but they usually have low quality and contain high free fatty acid (FFA). Feedstock with high acid value cannot directly undergo alkalinecatalyzed transesterification reaction since the FFAs react with the base catalyst and bring about saponification reaction. As a consequence, it diminishes the quantity of active catalyst and biodiesel yield [3]. Due to this fact, it is necessary to lower the FFA content in oil feed-stocks before running transesterification reaction of vegetable oils for biodiesel preparation. Thus, esterification reaction becomes a crucial step in biodiesel production process [4].

Esterification of FFA in vegetable oils are a reversible and slow reaction, hence, the presence of catalyst is important to enhance reaction rate. The most common catalyst for esterification reaction is strong mineral acid, such as sulfuric acid and hydrochloric acid. This homogeneous type of acid catalyst is powerful and has high catalytic activity. However, this catalyst brings about many environmental problems and costly product separation. Liquid mineral acids are hazardous, polluting, and corrosive [5]. Thus, the application of heterogeneous solid acid catalyst was found to be interesting to overcome the drawbacks of homogeneous catalyst. Recently, the employment of heterogeneous solid acid catalysts gains more significant attention in industrial process. It is as these types of catalysts are considered sustainable and powerful mainly in organic synthesis. Solid acid catalysts hold the benefits in terms of easy separation from the product and reusability of the catalyst. Solid acid catalyst could be classified into Brønsted and Lewis acid groups. The superiority of solid acid catalysts are ascertained by the strength, stability, number of active sites, and their economic viability [6].

There are several types of solid acid catalysts that can be employed to enhance the esterification reaction of fatty acids, namely supported heteropolyacids, sulfonic group sup- ported on ion-exchange resins, superacid sulfated zirconia catalyst, metal, and metallic salts. Heteropolyacids (HPAs), such as dodecatungstophosphoric acid $\left(\mathrm{H}_{3} \mathrm{PW}_{12} \mathrm{O}_{40}\right), \mathrm{H}_{4} \mathrm{Si}$ $\mathrm{W}_{12} \mathrm{O}_{40}, \quad \mathrm{H}_{3} \mathrm{PMo}_{12} \mathrm{O}_{40}$ and $\mathrm{H}_{4} \mathrm{SiMo}_{12} \mathrm{O}_{40}$, are among Brønsted acid catalysts and they are commonly supported on silica, mesoporous molecular sieve, and carbon. Supported HPAs have shown strong catalytic activity. However, they have limitation since these types of catalysts are only partially miscible with the reaction system [7]. Besides, supported HPAs catalysts encounter a problem of deactivation because of the coke formation on catalyst surface during organic reaction [8]. Another popular heterogeneous acid catalyst for esterification reaction is ion exchange resin. Ion exchange resins are made of a cross-link polymer matrix which contains active sites such as sulfonic acid group [6]. Sulfonic ion exchange resins can demonstrate high yield in esterification reaction, but it has low thermal stability which doesn't enable to run at temperature above 140 ${ }^{\circ} \mathrm{C}$ [7]. Concerning superacid sulfated zirconia catalyst, this catalyst is promising with high reaction conversion, but it is very expensive. To reduce the cost, sulfated zirconia is usually prepared on supports such as zeolites, mesoporous silica, and alumina. However, supported sulfated zirconia often deals with the problem of $\mathrm{Zr}$ or $\mathrm{S}$ leaching. The loss of sulfate ions $\left(-\mathrm{SO}_{3} \mathrm{H}\right.$ or $\mathrm{SO}_{4}$-) and $\mathrm{Zr}$ active sites will cause catalyst deactivation of activity and thus limit recycling of the catalyst [9].

Metal and metallic salt catalysts are the attractive alternative for fatty acid esterification, which could overcome the shortcoming of the other solid acid catalysts. Many of the recent work on the development of solid acid catalyst for esterification reaction are related to the use of metallic salt. Several previous works propose the application of tin compounds since tin metal exhibits a high Lewis metal acidity. Casas states that this metal is superior to the other transition metals in this succeeding sequence: $\mathrm{Sn}^{2+}>>\mathrm{Zn}^{2+}>\mathrm{Pb}^{2+} \approx \mathrm{Hg}^{2+}$ [7]. Among the tin compounds, tin(II) chloride demonstrates many benefits. It is simple, economically cost effective, commercially available, easy to handle, and active. It is also notably water tolerant, hence suitable for esterification reaction which results in water as byproduct. Tin(II) chloride is also reported to have complete solubility in methanol. However, da Silva stated that this catalyst is easily recovered by filtration, washed with hexane, and dried [5]. $\mathrm{SnCl}_{2}$ could be reused several times, with the same degree of activity. Considering those ad- 
vantages, tin(II) chloride catalyst was selected for improving the reaction rate of high FFA jatropha oil esterification in this work [10].

Besides employing a prospective solid acid catalyst, process intensification strategy should be applied to overcome some limitation of esterification reaction on the biodiesel production. Esterification is an equilibrium limited reaction, in which the reaction cannot reach the completion of the reaction due to the thermodynamic equilibrium constrain. Moreover, esterification reaction produces water as side product. It consequently requires a series of separation steps and apparatus to obtain biodiesel product with high purity. Based on this fact, process improvement is necessary for the conversion enhancement as well as simplifying the separation process [4]. In this work, process intensification was conducted by developing a multi-functional reactor, which integrates reaction and separation process in a single unit. This technique was designed for an in situ removal of the water produced from the liquid reaction phase in order to drive the equilibrium to the right, leading to the higher yield of the process. At the same time, it reduces equipment of the process.

Various types of multifunctional reactors which employ integrative reactive separation technology have been reported, namely reactive distillation, extractive distillation, reactive absorption, adsorptive reaction, membrane reactors, and so on [11, 12]. Among them, one remarkable innovation on multi-functional reactor development is the application of reactive distillation process. Reactive distillation (RD) combines distillation and reaction in a single column. It therefore simplifies the process flowsheet as well as reduces separation steps, and lowers the capital and operating cost. RD also enables the application of heat integration system, thus it is beneficial to decrease the demand for the process. RD is constructed as a single column divided into three sections, viz. reaction, rectifying, and stripping zones. This arrangement allows the continuous removal of one product from the reaction system. For equilibrium limited reaction, such as esterification reaction, it is favorable since the continuous removal of one product can shift the equilibrium towards the products formation [4]. Based on some above mentioned consideration, a process intensification on biodiesel production was proposed in this work by applying solid acid catalyst (tin(II) chloride) for high FFA in jatropha oil esterification using RD process. The purpose of this research was enhancing yield of the biodiesel production process using $\mathrm{RD}$ process in the presence of tin(II) chloride catalyst. The work focused on the application of heterogeneous catalyst and development of reactor technology.

\section{Experimentals}

\subsection{Materials}

The feedstock for biodiesel preparation using $\mathrm{RD}$ process in this work were crude jatropha oil obtained from P.T. Jatropha Green Energy, Kudus Indonesia and technical grade methanol. Jatropha oil has molecular weight, kinematic viscosity, and density (at $28^{\circ} \mathrm{C}$ ) of $868.3079 \mathrm{~g} / \mathrm{gmol}, 37.21 \mathrm{~mm}^{2} / \mathrm{s}$, and $0.94 \mathrm{~g} / \mathrm{m}$, respectively. Tin(II) chloride $\left(\mathrm{SnCl}_{2} .2 \mathrm{H}_{2} \mathrm{O}\right)$ from Merck and sodium hydroxide were employed as the catalysts for the esterification and transesterification reactions, respectively.

\subsection{Characterization of jatropha oil}

Determinations of acid value, saponification, Iodine, and peroxide values of the jatropha oil were carried out according to the standard AOCS methods [1]. Fatty acid composition of the crude jatropha oil feedstock was ascertained using Gas Chromatography - Mass Spectroscopy instrument (GC-MS Perkin Elmer, GC Clarus 680, MS Clarus SQ 8T). Gas chromatography instrument was run using the following operation condition: oven temperature started at $100{ }^{\circ} \mathrm{C}$, held for 5 minutes. Temperature increase was $10^{\circ} \mathrm{C} / \mathrm{min}$ until it reached the maximum temperature of $270{ }^{\circ} \mathrm{C}$, which was held for 8 minutes. Meanwhile, injector temperature was $300{ }^{\circ} \mathrm{C}$. Carrier gas was helium with the velocity of $0.5 \mathrm{~mL} / \mathrm{min}$ and splitting ratio was $1: 153$. Column dimension was $30 \mathrm{~mm}$ length and 250 micrometer in diameter. The Mass Spectroscopy was set with solvent delay of $0-2$ minutes and MS scan at 2-30 minutes with mass of 50-300.

\subsection{Esterification using reaction distilla- tion process}

The esterification reaction was performed to convert FFA in jatropha oil into methyl ester (biodiesel). Esterification reaction of FFA with methanol was conducted in an RD column as exhibited in Figure 1. This column was filled up by glass raschig ring packing and equipped with condensor, reflux control, reboiler, feed tanks, heater, peristaltic pump, and thermometer. Column and reboiler were heated by electrical heating coil and mantel, respectively, and kept at the certain temperature. Methanol feedstock was blended with a specific amount of 
tin(II) chloride catalyst which would provide the desired methanol-to-FFA molar ratio when mixed with the jatropha oil. The methanol/ catalyst premix and jatropha oil were initially put separately on the feedstock tanks. They were then introduced into the mixer tank for a preheating until reaching the reaction temperature. Afterwards, the reactants mixture flowed into the RD column. Each section of RD column functioned as a reactor and separation unit, as well. The mixture of reactants (methanol and oil) slowly moved along the column towards the the bottom and reacted in the liquid phase to produce methyl ester and water throughout the reactive section. A reboiler was built-in at the bottom of the column and worked to remove methanol from the product mixture prior to releasing to the decanter. The unreacted methanol vapor subsequently rose from the bottom to the top of the column. It was then condensed and refluxing back into the column to proceed the reaction. On the other hand, the product mixture discharging from the reboiler comprised two phases, viz. organic phase containing methyl ester-triglycerides mixture and aqueous phase containing water. The two phases were separated using decanter.

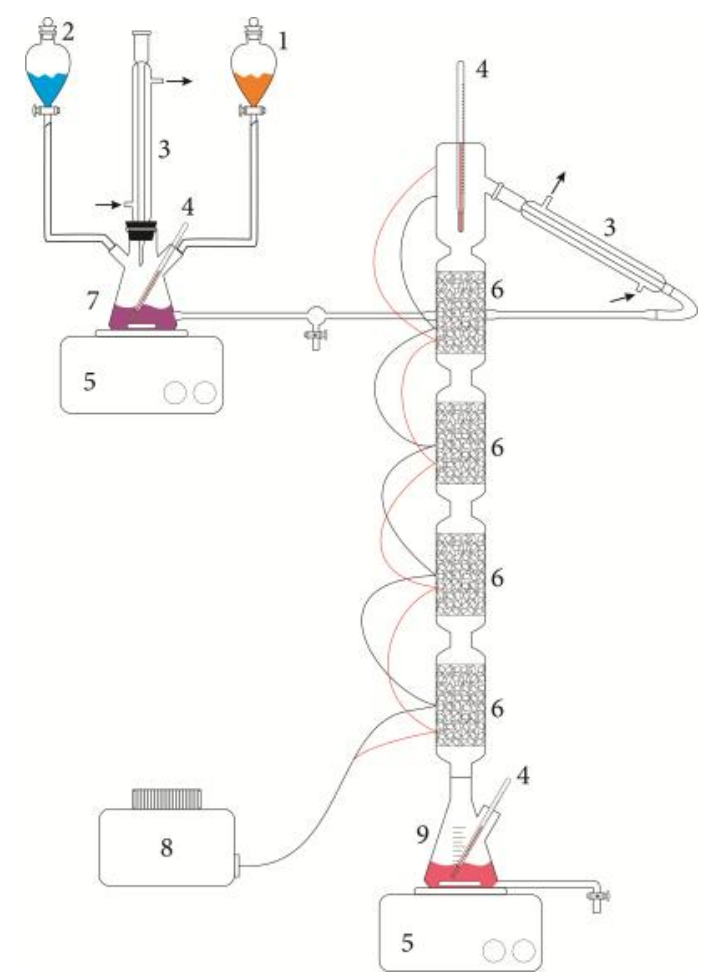

Figure 1. Scheme of reactive distillation column: (1) Jatropha oil feedstock tank; (2) Methanol \& tin(II) chloride feedstock tank; (3) Condenser; (4) Thermometer; (5) Heaterstirrer; (5) RD packed column; (6) Mixer tank; (7) Power stat; (8) Reboiler
The aqueous phase containing water was considered by-product and withdrawn, whereas the organic phase was taken as the product. To obtained high purity product, the organic phase was then filtered to remove the rest of solid acid catalyst. The esterification reaction of FFA using reactive distillation process were carried out by varying molar ratio of methanol to FFA (at $1: 15,1: 30$, and 1:60), reaction time (1-3 hours), and catalyst loading (at 3, 5, 10, and $15 \% \mathrm{w} / \mathrm{w}$ oil) at fixed reaction temperature of $60{ }^{\circ} \mathrm{C}$. However, the esterification product still contained triglycerides. Therefore, succeeding transesterification reaction was necessary for the completion of the biodiesel preparation.

\subsection{Transesterification process}

Transesterification reaction was conducted to convert the remaining triglyceride in the esterification product into methyl ester (biodiesel). Transesterification reaction of jatropha oil with methanol was conducted in the presence of sodium hydroxide catalyst in the similar RD column. The reaction was performed at $60^{\circ} \mathrm{C}$, molar ratio of methanol to oil of $6: 1$, and catalyst concentration of $1 \%$. Firstly, methanol feedstock was blended with a sodium hydroxide catalyst and placed in the feedstock tank. The esterified jatropha oil was also put on the other feedstock tank. They were then introduced into the mixer tank for a preheating until attaining the reaction temperature. Subsequently, the reactants mixture flowed into the RD column. Each section of RD column worked as an integrated reactor and separation unit. The mixture of reactants (methanol and oil) slowly moved along the column towards the the bottom and reacted in the liquid phase to produce methyl ester and glycerol throughout the reactive section. A reboiler was built-in at the bottom of the column and served to remove methanol from the product mixture prior to releasing to the decanter. The unreacted methanol vapor subsequently rose from the bottom to the top of the column. It was afterwards condensed and refluxing back into the column to continue the reaction. On the other hand, the product mixture discharging from the reboiler consisted of two phases, viz. the organic phase containing methyl ester and the remaining triglycerides mixture, and the aqueous phase containing glycerol. The two phases were separated using decanter. The aqueous phase was considered by-product and withdrawn, whereas the organic phase was taken as the biodiesel product. This biodiesel final product was then analyzed to determine its fuel properties. 


\subsection{Fuel properties}

The fuel properties of the jatropha oil biodiesel were assessed the following standard methods: calor value (dynamic method), water content (Karl Fischer), kinematic viscosity (ASTM D445), density (ASTM D93), and diesel index (ASTM D613). Fatty acid composition of the jatropha biodiesel was determined using Gas Chromatography - Mass Spectroscopy (GC-MS) instrument (GC-MS Perkin Elmer, GC Clarus 680, MS Clarus SQ 8T). GC-MS instrument was set as the operation condition run for the jatropha oil analysis.

\section{Results and Discussion}

\subsection{Characterization of jatropha oil}

According to the AOCS analysis method, the saponification, Iodine, and peroxide numbers of crude jatropha oil were found to be $78.42 \mathrm{mg}$ $\mathrm{KOH} / \mathrm{g}, 112.2 \mathrm{mg}$ iod $/ \mathrm{g}$ oil, and $27.2 \mathrm{meq} / \mathrm{kg}$ oil, respectively. It was also revealed that the acid value was $18.8 \mathrm{mg} \mathrm{KOH} / \mathrm{g}$ oil, corresponding to a FFA level of $9.4 \%$. Determination of the fatty acid composition of this crude jatropha oil was conducted using GC-MS analysis. It was demonstrated that the main types of fatty acids constituting the oil were oleic acid (33.38\%) at the retention time of 19.36 minutes and linoleic acid (28.10\%) at the retention time of 25.46 minutes. This composition was found slightly different from the Mexican jatropha oil which dominantly consists of $47.20 \%$ of oleic acid, $27.60 \%$ linoleic acid, and $16.09 \%$ palmitic acid [13]. However, it is comparable to the general chemical composition of jatropha oil which comprises 34.30$45.80 \%$ oleic acid, $29.00-44.20 \%$ linoleic acid, and 14.1-15.3\% palmitic acid [14].

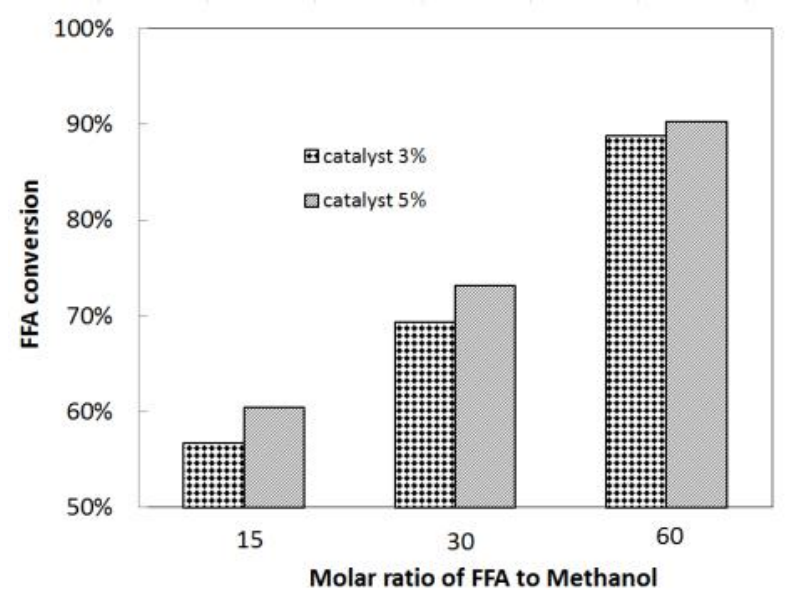

Figure 2. Conversion (\%) of esterification reaction at different molar ratio for the process conducted at catalyst loading of 3 and $5 \%$ and reaction temperature of $60^{\circ} \mathrm{C}$

\subsection{Optimization of reaction parameters}

Optimization of the reaction parameter of the jatropha oil esterification using continuous flow RD system in the presence of tin(II) chloride catalyst was performed experimentally. The effects of molar ratio of methanol to FFA jatropha oil at the feed stream, catalyst loading, and the duration of reaction time were evaluated. To further understand the impact of process intensification using multifunctional reactor, the reaction conversion obtained using RD process was compared to the result given by the batch reactor.

\subsection{Effect of feed molar ratio of methanol and jatropha oil}

Based on the stoichiometric proportion, esterification reaction merely requires one mole of alcohol and one mole of fatty acid. However, esterification is a reversible reaction, thus the excess amount of alcohol is necessitated to drive the reaction towards product formation. It is suggested that fatty acid esterification requires markedly high molar ratio of FFA to methanol, approximately $1: 15$ to $1: 275$, in order to achieve high reaction conversion [1]. In this work, the effect of molar ratio of FFA to methanol for the FFA esterification in reactive distillation column was evaluated by varying the molar ratio at 1:15, 1:30, and 1:60 with the reaction temperature of $60{ }^{\circ} \mathrm{C}$ and catalyst loading of 3 and $5 \% \mathrm{w} / \mathrm{w}$ oil. The experimental data is displayed in Fig. 2. It was disclosed that the best molar ratio of FFA to oil was 1:60 both for the catalyst loading of 3 and $5 \% \mathrm{w} / \mathrm{w}$ oil, which was in accordance with the classical Le Chatelier principle. This result was significantly higher compared to the result reported by Cardoso et al. [15]. It is stated that the esterification of oleic acid using ethanol in the presence of tin (II) chloride in a batch reactor requires molar ratio of 1:120 after 12 hours of the reaction, giving reaction conversion of $87 \%$. The FFA esterification in this work needed less amount of alcohol at the shorter reaction time since the RD arrangement allows the recovery of methanol by condensing the methanol vapor at the top of the column, and then send it back to the reactive zone. The methanol recovery will increase the molar ratio of methanol to oil in the column, which will be higher than the molar ratio of the reactant in feed mixture. This situation will drive the reaction equilibrium into the product formation. It has proved that $\mathrm{RD}$ application on biodiesel production will result in the enhanced yield at lessened amount 
of methanol in the feed stream in comparison with the conventional process [16].

\subsection{Effect of catalyst loading and types of catalyst}

The amount of catalyst usually significantly influences the rate of the reaction, particularly for the equilibrium-limited or reversible reactions. For the heterogeneous catalyzed reaction, the higher catalyst loading denotes the higher availability of the active sites which perform to increase the reaction rate $[17,18]$. In this work, the effect of catalyst loading was studied at $3,5,10$, and $15 \% \mathrm{w} / \mathrm{w}$ oil for the reactions carried out at $60{ }^{\circ} \mathrm{C}$ with molar of FFA to methanol of 1:60 as exhibited in Figure 3. It was shown that reaction rate remarkably enhanced when the catalyst loading increased from 3 to $5 \%$. However, it dramatically decreased with the catalyst loading of 10 and $15 \%$. For that reason, the optimum catalyst loading in this work was $5 \%$ w/w oil. Therefore, the optimized condition was the FFA esterification performed in the RD column with catalyst loading of $5 \% \mathrm{~g} / \mathrm{g}$ oil, molar ratio of $\mathrm{FFA}$ to methanol of 1:60, and reaction temperature of $60{ }^{\circ} \mathrm{C}$, which provided reaction conversion of 90\%. Enhancement of the reaction conversion with the presence of $\operatorname{tin}(\mathrm{II})$ chloride catalyst occurs due the following mechanism. Sn(II) catalyst activates the carbonyl group of the fatty acid, promoting its attack to the hydroxyl group of methanol. In that way, it increases the formation of methyl ester [19]. The more detailed mechanism was described by Casas [7]. It is stated that Lewis acid catalyzed reaction, the acid site of free tin orbital engages with the

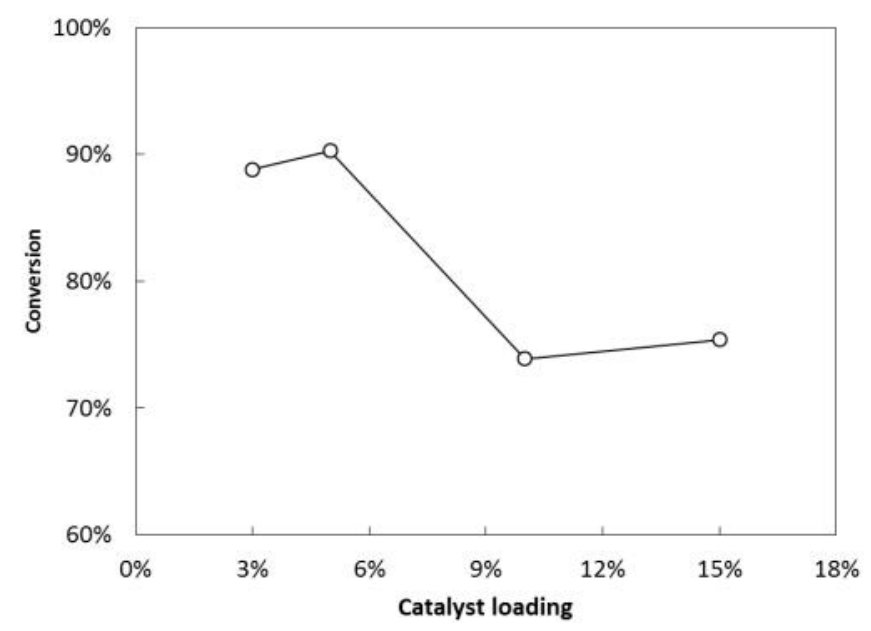

Figure 1. Conversion (\%) of esterification reaction at different catalyst loading for the process conducted at molar ratio of FFA to methanol of 1:60 and reaction temperature of $60^{\circ} \mathrm{C}$ oxygen of the carbonyl group. This condition will raise the electrophilicity of the attached carbon atom. It hence improves the susceptibility to nucleophilic attack. As consequence, it enables the fatty acid compounds to readily access the catalyst active sites and activates the reaction [7]. Regarding the catalytic activity of the $\mathrm{SnCl}_{2} .2 \mathrm{H}_{2} \mathrm{O}$, it has been reported in the literature that the activation energy of tin(II) chloride catalyzed-reaction is $46.7 \mathrm{~kJ}$. The kinetic model follows the first order with dependence on $\mathrm{SnCl}_{2}$ concentration.

To provide more evidence on the advantage of the employment of tin(II) chloride catalyst, performance of this solid catalyst was compared to Amberlyst-15 heterogeneous catalyst and the classical homogeneous strong acid catalyst (sulfuric acid). It was found that the conversions of FFA esterification reactions conducted in similar RD apparatus with identical operation condition in the presence of Amberlyst-15 and sulfuric acid were 30 and $94.71 \%$, respectively. It can be emphasized that tin(II) chloride exhibited excellent performance compared to Amberlyst-15 solid acid catalyst. Moreover, tin(II) catalyst provided a comparable conversion with sulfuric acid, but this solid catalyst is superior in terms of environmental and sustainability aspects.

The different behavior between tin(II) chloride catalyst and Amberlyst- 15 could be described for the following reason. Tin(II) chloride is among Lewis acid catalyst, conversely Amberlyst-15 is a Brønsted acid type catalyst. Brønsted acid catalytic activity is commonly inhibited by the presence of water. In this case, esterification reaction generates water as by-product. Many studies have revealed that water will poison the active sites on Amberlyst-15, leading to the decrease of the reaction conversion. In contrast, Lewis acid is found to be more water tolerant that Brønsted acid. Accordingly, tin(II) chloride, which is among Lewis acid catalyst, provides much higher conversion in the esterification reaction in comparison with Amberlyst-15, which includes Brønsted acid catalyst [19].

\subsection{Effect of the duration of reactive dis- tillation process}

Freedman et al. [20] stated that for batch reaction, reaction conversion increased with the reaction time. However, for continuous process, the duration of the process would not result in the different reaction conversion when steady state operation has been reached. To evaluate the effect of duration of reactive process on the reaction conversion, 
samples were withdrawn periodically at 1-3 hours. For the FFA esterification carried out at $60{ }^{\circ} \mathrm{C}$, molar ratio of FFA to methanol of $1: 30$, and catalyst loading of $3-15 \%$ g catalyst/g oil, it was shown that the conversion obtained at various process durations were practically identical. It means that the FFA esterification run by continuous reaction distillation process has attained steady state condition as presented in Figure 4.

In this work, esterification reaction in the presence of tin(II) chloride catalyst was performed in a continuous RD column. This type of reactor is designed as a multi-functional reactor which integrates reaction and separation in a single unit. It therefore simplifies the process and reduces the operation as well as capital costs [1, 21]. In addition, reactive distillation technology is developed to overcome the problem of equilibrium-limited reaction, for instance esterification, which usually provides low reaction conversion. In a reactive distillation process, there is a continuous product removal in the reaction system which will shift the equilibrium to the right. Thus, it enhances the reaction conversion [12, 22]. Those above mentioned advantages could be comprehended by comparing the experimental data of reactive distillation process and that of batch process as shown in Figure 5.

\subsection{Comparison between reactive distilla- tion and batch process}

This work also aims at the development of reactive distillation as part of process intensification technology for biodiesel production. The application of RD as one type of multifunctional

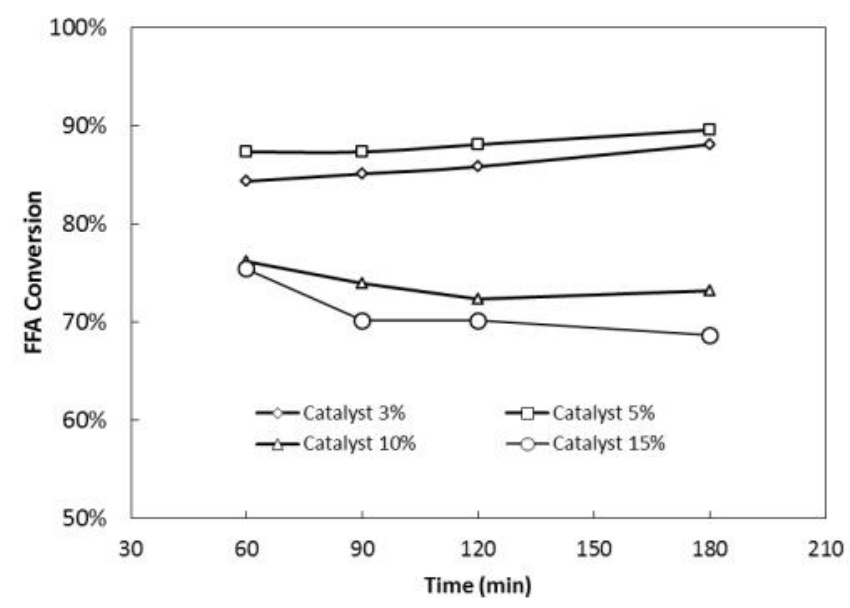

Figure 4. Conversion (\%) of esterification reaction at different catalyst loading and process duration for the process conducted at molar ratio of FFA to methanol of $1: 30$ and reaction temperature of $60^{\circ} \mathrm{C}$ reactor is expected to provide a better performance of the process than batch process. Many researches have described the advantages of RD application for biodiesel production through simulation studies. However, this work intends to provide experimental evidence of the improvement given by the RD technology. Figure 5 compared the FFA conversion resulted by reactive distillation and batch process for jatropha oil esterification employing $10 \%$ concentration of tin(II) chloride catalyst, which were conducted at $60{ }^{\circ} \mathrm{C}$ at various molar ratio of reactants. The experimental data of the batch process was taken from the literature [10]. It was revealed that performance of the reactive distillation process at this condition was constantly superior to that of the batch process. Additionally, the optimized conversion given by reactive distillation process was $90 \%$ at the following operation condition: catalyst loading of $5 \% \mathrm{~g}$ catalyst/g oil, molar ratio of FFA to methanol of 1:60, residence time of 1.1 minutes, and reaction temperature of $60{ }^{\circ} \mathrm{C}$. Conversely, the batch process provided the optimized conversion of $78 \%$ at the subsequent condition: catalyst loading of $10 \% \mathrm{~g}$ catalyst/g oil, molar ratio of FFA to methanol of $1: 120$, reaction time of 4 hours, and reaction temperature of $60{ }^{\circ} \mathrm{C}$. The reaction utilizing reactive distillation process was beneficial since it required less amounts of methanol, catalyst, as well as reaction time. This phenomenon occurred since vapor-liquid and reaction equilibriums took place simultaneously in the reactive distillation column. In the reaction zone, in situ product removal from the liquid phase was continuously carried out [23, 24]. Afterwards, unreacted

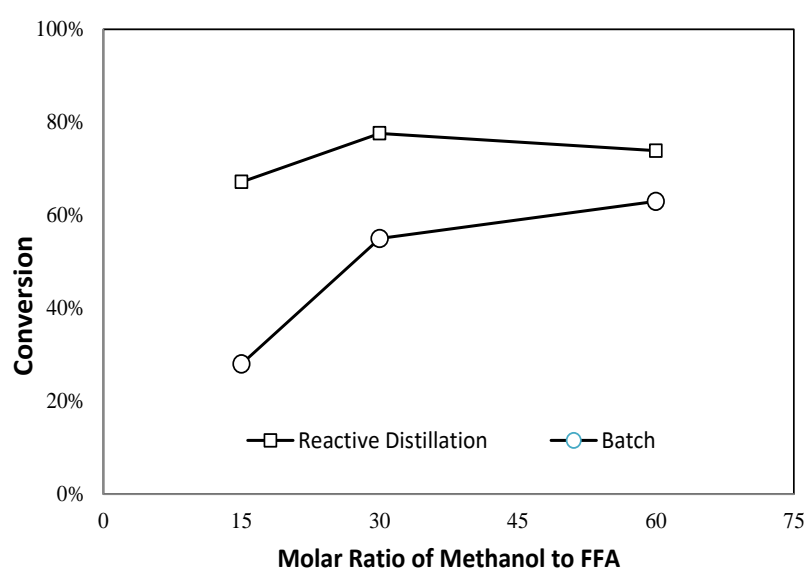

Figure 5. Conversion (\%) of esterification reaction in different molar ratio of methanol to FFA in jatropha oil for reactive distillation and batch process at reaction temperature of $60{ }^{\circ} \mathrm{C}$ and tin(II) chloride catalyst loading of $10 \%$ 
methanol was constantly recycled into the column, thus enhancing molar ratio of the reactants inside the column and forcing the equilibrium towards methyl ester formation.

\subsection{Fuel properties}

The esterification reaction of high FFA jatropha oil was subsequently pursued by transesterification reaction for the completion of the biodiesel production. Transesterification was carried out at $60^{\circ} \mathrm{C}$, with molar ratio of methanol to oil of 1:6 and $\mathrm{NaOH}$ catalyst of $1 \%$ using the similar reactive distillation apparatus. The jatropha biodiesel product resulted from this two steps process disclosed the following characteristic: ester content, kinematic viscosity, density, and caloric value of the fuel were $97.79 \%, 5.051 \mathrm{~mm}^{2} / \mathrm{s}, 0.842 \mathrm{~g} / \mathrm{mL}$, and 113.491 $\mathrm{J} / \mathrm{g}$, respectively. These properties have satisfied the ASTM D 6751 standard for diesel fuel [1]. Furthermore, fatty acid composition of jatropha biodiesel as determined using GC-MS instrument was presented on Table 1.

\section{Conclusions}

The application of tin(II) chloride catalyst for high FFA jatropha oil esterification using continuous reactive distillation have been studied. The reaction conversion reached $90 \%$ at the following optimized condition: catalyst loading of $5 \% \mathrm{~g}$ catalyst/g oil, molar ratio of $\mathrm{FFA}$ to methanol of 1:60, and reaction temperature of $60{ }^{\circ} \mathrm{C}$. This conversion was significantly higher than that achieved by the reaction using Amberlyst 15. It is because tin(II) chloride is among Lewis acid catalyst which is highly water tolerant in comparison with Amberlyst 15 which is among Brønsted acid catalyst. The performance of $\mathrm{RD}$ process was also furthermore compared with batch process. It was found that the RD process provided higher conversion than batch process. It is evidence that

Table 1. Fatty acid composition of jatropha biodiesel

\begin{tabular}{lcc}
\hline \multicolumn{1}{c}{ Compounds } & $\begin{array}{c}\text { Concentration } \\
(\%)\end{array}$ & $\begin{array}{c}\text { Retention } \\
\text { Time (min) }\end{array}$ \\
\hline Methyl Palmitoleate & 1.58 & 17.800 \\
Methyl Palmitate & 17.76 & 18.090 \\
Methyl Oleate & 68.11 & 19.890 \\
Methyl Stearate & 10.34 & 20.011 \\
Others & 2.21 & 23.462 \\
\hline
\end{tabular}

reactive distillation technology offers benefits as part of process intensification for biodiesel production. Moreover, evaluation on the running time of the reactive distillation process has depicted that the system has attained the steady state and stability condition. For the completion of the biodiesel synthesis, the esterification was followed by transesterification reaction using the similar reactive distillation column. Jatropha biodiesel produced in this process has ester content of $97.79 \%$. Viscosity, density, and caloric value of the fuel were $5.051 \mathrm{~mm}^{2} / \mathrm{s}, 0.842 \mathrm{~g} / \mathrm{mL}$, and $113.491 \mathrm{~J} / \mathrm{g}$, respectively. Biodiesel fuel characteristic has met the ASTM D 6751 standard for diesel fuel in terms of the properties tested in this work. In conclusion, utilization of tin(II) chloride catalyst in the reactive distillation system is prospective for the future biodiesel production technology.

\section{Acknowledgments}

The authors would like to acknowledge the financial support from the Indonesian Directorate of Higher Education (DIKTI) through Hibah Bersaing Research Grant.

\section{References}

[1] Alhassan, F.H., Yunus, R., Rashid, U., Sirat, K., Islam, A., Lee, H.V., Taufiq-Yap, Y.H. (2013). Production of Biodiesel from Mixed Vegetable Oils Using Ferric Hydrogen Sulphate as An Effective Reusable Heterogeneous Solid Acid Catalyst. Appl. Catal. A: General, 456: 182-187.

[2] Neumann, K., Werth, K., Martín, A., Górak, A. (2015). Biodiesel Production from Waste Cooking Oils through Esterification: Catalyst Screening, Chemical Equilibrium and Reaction Kinetics. Chem. Eng. Res. Dev. (in press)

[3] Kostić, M.D., Veličković, A.V., Joković, N.M., Stamenković, O.S., Veljković, V.B. (2016). Optimization and Kinetic Modeling of Esterification of the Oil Obtained from Waste Plum Stones as A Pretreatment Step in Biodiesel Production. Waste Management, 48: 619-629.

[4] Banchero, M., Kusumaningtyas, R.D., Gozzelino. G. (2014). Reactive Distillation in the Intensification of Oleic Acid Esterification with Methanol - A Simulation CaseStudy. Journal of Industrial and Engineering Chemistry, 20(6): 4242-4249.

[5] Da Silva, M.J. Cardoso, A.L., Natalino, R. (2010). Bioenergy II: Tin Catalysed Esterification of Free Fatty Acids. International Journal of Chemical Reactor Engineering, 8. 
[6] Sharma, Y.C., Singh, B., (2011). Advancements in Solid Acid Catalysts for Ecofriendly and Economically Viable Synthesis of Biodiesel. Biofuels, Bioprod. Bioref. 5: 69-92.

[7] Casas, A., Ramos, M.J., Rodríguez, J.F., Pérez, A. (2013). Tin Compounds as Lewis Acid Catalysts for Esterification and Transesterification of Acid Vegetable Oils. Fuel Processing Technology, 106: 321-325.

[8] Kozhevnikov, I.V. (1998). Catalysis by Heteropoly Acids and Multicomponent Polyoxometalates in Liquid-Phase Reactions. Chem. Rev. 98: 98-171.

[9] Khire, H., Bhagwat, P.V., Fernandes, M., Gangundi, P.B., Vadalia, H. (2012). Esterification of Lower Aliphatic Alcohols with Acetic Acid in Presence of Different Acid Catalysts. Indian Journal of Chemical Technology, 19, 342-350.

[10] Kusumaningtyas, R.D., Handayani, P.A., Rochmadi, Purwono, S., Budiman, A. (2014). Tin(II) Chloride Catalyzed Esterification of High FFA Jatropha Oil: Experimental and Kinetics Study. International Journal of Renewable Energy Development, 3(2): 75-81.

[11] Banchero, M., Gozzelino, G. (2015). $\mathrm{Nb}_{2} \mathrm{O}_{5}$ Catalyzed Kinetics of Fatty Acids Esterification for Reactive Distillation Process Simulation. Chem. Eng. Res. Dev., 100: 292-301.

[12] Kusumaningtyas, R.D., Purwono, S., Rochmadi, Budiman, A. 2014. Graphical Exergy Analysis of Reactive Distillation Column for Biodiesel Production. Int. J. Exergy, 15(4): 447-467.

[13] Sanchez-Arreola, E., Martin-Torres, G., Lozada-Ramírez, J.D., Hernandez, L.R., Bandala-Gonzales, E.R., Bach, H. (2015). Biodiesel Production and De-Oiled Seed Cake Nutritional Values of A Mexican Edible Jatropha Curcas. Renewable Energy, 76: 143-147.

[14] Praptijanto, A., Agustian, E., Putrasari, Y., Sebayang, D., Rus, A.Z.M., Hasan, S., and Untoro, P. (2015). Sonochemistry Approach to Reducing Biodiesel Reaction Time from Jatropha Curcas Oil by Clamp on Tubular Reactor, Energy Procedia, 68: 480-489.

[15] Cardoso, A.L., Neves, S.C.G., da Silva, M.J. (2009). Kinetic Study of Alcoholysis of the Fatty Acids Catalyzed by Tin Chloride (II): An Alternative Catalyst for Biodiesel Production. Energy and Fuels, 23(3): 1718-1722.
[16] Boon-anuwat, N., Kiatkittipong, W., Aiouache, F., Assabumrungra, S. (2015). Process Design of Continuous Biodiesel Production by Reactive Distillation: Comparison Between Homogeneous and Heterogeneous Catalysts. Chemical Engineering and Processing: Process Intensification, 92: 33-44

[17] Srilatha, K., Lingaiah, N., Devi, B.L.A.P., Prasad, R.B.N., Venkateswar, S., Prasad, P.S.S. (2009). Esterification of Free Fatty Acids for Biodiesel Production over Heteropoly Tungstate Supported on Niobia Catalysts. Applied Catalysis A: General, 365(1): 28-33.

[18] Yadav, G.D., Yadav, A.R. (2012). Insight into Esterification of Eugenol to Eugenol Benzoate Using A Solid Super Acidic Modified Zirconia Catalyst UDCaT-5. Chemical Engineering Journal, 192: 146-155.

[19] Ferreira, A.B., Cardoso, A.L., da Silva, M.C. (2012). Tin-Catalyzed Esterification and Transesterification Reactions: A Review. ISRN Renewable Energy, 142857: 1-13.

[20] Freedman, B., Pryde, E.H., Mounts, T.L. (1984). Variables Affecting the Yields of Fatty Esters from Transesterified Vegetable Oils. J. Am. Oil Chem. Soc. 61(10): 16381643.

[21] Dimian, A.C., Bildea, C.S., Omota, F., Kiss. A.A. (2009). Innovative Process for Fatty Acid Esters by Dual Reactive Distillation. Comput. Chem. Eng., 33(3): 743-750.

[22] Gómez-Castro, F.I., Rico-Ramírez, V., Segovia-Hernández, J.G., Hernández-Castro. S. (2011). Esterification of Fatty Acids in A Thermally Coupled Reactive Distillation Column by the Two Step Supercritical Methanol Method. Chem. Eng. Res. Des., 89: 480-490.

[23] Taylor, R., Krishna, R. (2000). Modelling Reactive Distillation. Chem. Eng. Sci., 55: 5183-5229.

[24] Kusmiyati, K, Sugiharto, A. (2010). Production of Biodiesel from Oleic Acid and Methanol by Reactive Distillation. Bulletin of Chemical Reaction Engineering \& Catalysis, 5(1): $1-6$

Selected and Revised Papers from The $2^{\text {nd }}$ International Conference on Chemical and Material Engineering 2015 (ICCME 2015) (29-20 September, 2015, Semarang, Indonesia)

(http://econference.undip.ac.id/index.php/iccme/2015) after reviewed by Peer-Reviewers of ICCME 2015 and BCREC Journal 